\title{
Increased native T1-values at the interventricular insertion regions of precapillary pulmonary hypertension patients
}

\author{
Onno A Spruijt ${ }^{1}$, Harm-Jan Bogaard ${ }^{1}$, Loek Vissers ${ }^{1}$, Anton Vonk-Noordegraaf ${ }^{1}$, Tim J Marcus ${ }^{2 *}$ \\ From 18th Annual SCMR Scientific Sessions \\ Nice, France. 4-7 February 2015
}

\section{Background}

Due to pressure overload of the right ventricle (RV) in precapillary pulmonary hypertension $(\mathrm{PH})$ patients, the interventricular insertion regions showed Late Gadolinium Enhancement (LGE), representing fibrosis (Blyth et al, Eur Heart J, 2005 Oct;26(19):1993-9). Another promising technique to characterize myocardium is native T1-mapping. Native T1-mapping can be assessed without contrast agents and the myocardial $\mathrm{T} 1$ can be quantified without the need of a reference area. Therefore, the aim of this study was to characterize the interventricular insertion regions in precapillary $\mathrm{PH}$ patients using native T1-mapping.

\section{Methods}

70 precapillary PH patients (mean pulmonary artery pressure $=47 \pm 13 \mathrm{mmHg}$ ) were included. Native T1-mapping was acquired on a Siemens $1.5 \mathrm{~T}$ Avanto scanner. A modified Look-Locker inversion-recovery (MOLLI) pulse sequence was used on a mid-ventricular short axis imaging plane. Three, three, and five non-segmented images were acquired at end-diastole of consecutive heart beats to sample the recovery of longitudinal magnetization after the inversion pulse. Minimal inversion time was $100 \mathrm{~ms}$ (Messroghli et al, JMRI 26:1081-1086, 2007). Motion compensation was applied. Native T1-values were assessed using regions of interest (ROIs) at the interventricular insertion regions, the RV free wall and left ventricular (LV) free wall.

\section{Results}

Native T1-values of the RV were significantly higher than native T1-values of the LV $(\mathrm{p}=0,038)$. Native T1-values at the interventricular insertion regions were significantly higher compared to the RV free wall $(\mathrm{p}<0.001)$ and LV free wall $(\mathrm{p}<0.001)$ (Figure 1$)$. Native T1-values at the insertion regions were significantly related to right atrial pressure (pearson $\mathrm{r}=0.310 ; \mathrm{p}=0.01$ ), $\mathrm{RV}$ end-diastolic volume (pearson $\mathrm{r}=0.376 ; \mathrm{p}=0.001$ ), $\mathrm{RV}$ ejection fraction (pearson $\mathrm{r}=-0.282 ; \mathrm{p}=0.018$ ) and NT pro-BNP (pearson $\mathrm{r}=0.392 ; \mathrm{p}=0.001$ ).

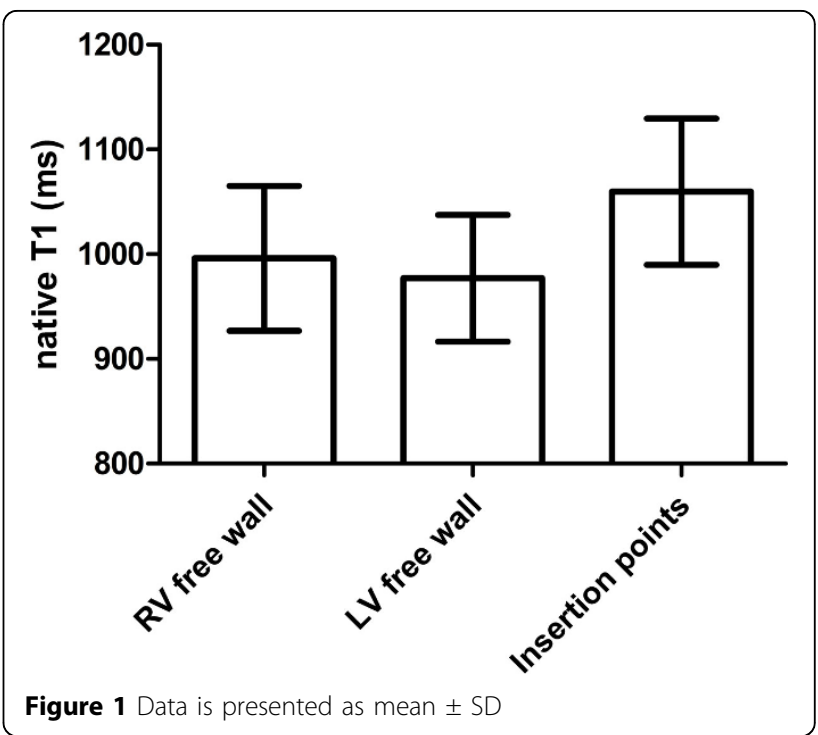




\section{Conclusions}

Native T1-values at the interventricular insertion regions are significantly increased in precapillary $\mathrm{PH}$ and are related to disease severity. This finding is in line with previous $\mathrm{PH}$ studies using LGE where contrast-enhancement was observed in the same region. Our results show that native T1-mapping can be an alternative for the characterization of the interventricular insertion regions without the use of contrast agents.

\section{Funding}

N/A.

\section{Authors' details}

${ }^{1}$ Department of Pulmonary Medicine, VU University Medical Center, Amsterdam, Netherlands. ${ }^{2}$ Department of Physics and Medical Technology, VU University Medical Center, Amsterdam, Netherlands.

Published: 3 February 2015

doi:10.1186/1532-429X-17-S1-Q44

Cite this article as: Spruijt et al.: Increased native T1-values at the interventricular insertion regions of precapillary pulmonary

hypertension patients. Journal of Cardiovascular Magnetic Resonance 2015 17(Suppl 1):Q44.

Submit your next manuscript to BioMed Central and take full advantage of:

- Convenient online submission

- Thorough peer review

- No space constraints or color figure charges

- Immediate publication on acceptance

- Inclusion in PubMed, CAS, Scopus and Google Scholar

- Research which is freely available for redistribution

Submit your manuscript at www.biomedcentral.com/submit
C Biomed Central 